\title{
ANÁLISE COMPARATIVA ENTRE O TEXTO DRAMÁTICO EMIGRANCI DE SŁAWOMIR MROŻEK E O POEMA PAN COGITO - POWRÓT DE ZBIGNIEW HERBERT: A QUESTÃO DA EMIGRAÇÃ̃O
}

\author{
A Comparative Analysis of the Dramatic Text "Emigranci" of Stawomir \\ Mrozek and the Poem "Pan Cogito - Powrót" of Zbigniew Herbert: The \\ Question of Emigration
}

\author{
Milena WOITOVICZ CARDOSO \\ Universidade Federal do Paraná \\ milenawc@gmail.com \\ https://orcid.org/0000-0003-0592-3122
}

\begin{abstract}
RESUMO: No presente artigo é apresentada uma análise comparativa entre dois textos literários poloneses produzidos no contexto da vigência de um Estado Totalitário na Polônia, a saber, PRL - Polska Rzeczpospolita Ludowa (República Popular da Polônia). Os textos selecionados são: o texto dramático Emigranci (Os Emigrantes) de Sławomir Mrożek e o poema Pan Cogito - Powrót (Senhor Cogito - O Regresso) de Zbigniew Herbert, pois em ambos é possível observar a questão da emigração vivenciada por muitos poloneses nesse período. Para isso, são apresentadas brevemente a biografia de cada autor, o contexto histórico da produção dessas obras, para no fim, apresentar a interpretação comparada entre os textos, utilizando-se trechos do poema e do texto dramático.
\end{abstract} PALAVRAS-CHAVE: Zbigniew Herbert; Sławomir Mrożek; PRL Polska Rzeczpospolita Ludowa; Interpretação comparada.

\begin{abstract}
This article brings a comparative analysis between two Polish literary texts produced in the context of the existence of a Totalitarian State in Poland, namely PRL - Polska Rzeczpospolita Ludowa (Polish People's Republic). The selected texts are: the dramatic text Emigranci (The Emigrants) by Sławomir Mrożek and the poem Pan Cogito - Powrót (Mr. Cogito - The Return) by Zbigniew Herbert. These two texts were chosen, because in both it is possible to observe the issue of emigration experienced by many Polish people in that period. For that, we briefly present the biography of each author and the historical context of the production of these works, in order to show the comparative interpretation between the texts, using excerpts from the poem and the dramatic text. KEY-WORDS: Zbigniew Herbert; Sławomir Mrożek; PRL - Polska Rzeczpospolita Ludowa; Comparative Analysis.
\end{abstract}


STRESZCZENIE: Przedmiotem niniejszego artykułu jest analiza porównawcza dwóch polskich tekstów literackich, które zostały napisane $\mathrm{w}$ kontekście istnienia władzy państwa totalitarnego $\mathrm{W}$ Polsce, a mianowicie PRL, Polskiej Rzeczypospolitej Ludowej. Wybrane teksty to sztuka Emigranci Sławomira Mrożka oraz wiersz Pan Cogito - Powrót Zbigniewa Herberta. Oba teksty opisują problem emigracji, którego wielu Polaków doświadczyło w tym okresie. Zostały zaprezentowane krótkie biografie każdego autora, kontekst historyczny powstania obu dzieł, aby na końcu przedstawiać analizę porównawczą fragmentów dramatu i wiersza. SŁOWA KLUCZOWE: Zbigniew Herbert; Sławomir Mrożek; PRL Polska Rzeczpospolita Ludowa; analiza porównawcza.

O presente trabalho é uma análise comparativa entre dois textos da Literatura Polonesa: o texto dramático Emigranci de Sławomir Mrożek e o poema Pan Cogito - Powrót de Zbigniew Herbert, com a intenção de observar a questão da emigração presente neles. Primeiramente, será apresentada breve biografia de cada autor das obras mencionadas, para então apresentar o contexto histórico em que as obras foram escritas. Em seguida será apresentada a interpretação comparada.

\section{BREVE BIOGRAFIA DOS AUTORES}

\section{Sławomir Mrożek}

Sławomir Mrożek nasceu em 29 de junho de 1930, em Borzęcin, na Polônia e faleceu, aos 83 anos, em 15 de agosto de 2013, em Nice na França. De certa forma, esses acontecimentos e lugares sintetizam a vida que o escritor, dramaturgo e cartunista teve. Iniciou a carreira como jornalista e desenhista. Interessante pontuar que não terminou os estudos universitários (iniciou Arquitetura, depois Estudos Orientais e História da Arte). Seus desenhos satíricos ganharam popularidade e ainda, escreveu reportagens sobre a construção do socialismo (DĄBROWSKA, 2013, sem paginação).

Mrożek inicia seu percurso na dramaturgia, especificamente, no ano de $1958 \mathrm{com}$ a comédia Policja ( $A$ Polícia), na qual retrata um Estado Totalitário que a todo momento precisa de oposição, e para alcançar isso, manipula a noção de liberdade (DĄBROWSKA, 2013, sem paginação). Nessa sua peça de estreia, já é possível vislumbrar um problema importante, que será retomado mais à frente. Para muitos, Mrożek seria um surrealista, 
sendo também relacionado com o Teatro do Absurdo ocidental. Cabe citar, no entanto, um dos diversos críticos que fazem ressalvas a essas classificações: Tadeusz Nyczek ressalta que o absurdo em Mrożek reside na observação da realidade social concreta durante a República Popular da Polônia ${ }^{1}$, diferente da abordagem do absurdo entre os autores ocidentais, que exploram em suas obras uma realidade especulativa, metafórica (DĄBROWSKA, 2013, sem paginação). Essa característica também é percebida por Martin Esslin, que criou o conceito Teatro do Absurdo em obra homônima, que afirmou:

\begin{abstract}
Enquanto no Ocidente os autores do teatro do absurdo aproveitavam em seus dramas a poética onírica, o teatro de Mrożek e de seus semelhantes na Europa Central (como Różewicz na Polônia, Havel e Klima na Tchecoslováquia, ou Orkeny na Hungria) abertamente rejeitou não apenas as bases do realismo socialista ou o realismo 'épico' de Brecht, mas também as convenções realistas do teatro de rua daqueles tempos. Utilizou em vez disso a alegoria satírica e desse modo se tornou, de fato, o ponto máximo do realismo (ESSLIN, 1991, p. 211 apud KILANOWSKI, 2016).
\end{abstract}

O dramaturgo emigrou da Polônia em 1963, vivendo muitos anos longe de sua pátria. Um reflexo disso foi Cezary Michalski considerar Mrożek como um emigrante, após o primeiro ter contato com a obra Dziennik powrotu (Diário do retorno) de autoria do escritor. Para confirmar sua percepção Michalski destacou duas datas significativas: 1) outubro de 1963, em que o dramaturgo decidiu ficar na Itália, mesmo com documentação irregular, e suas obras circularam pela Polônia em publicações e encenações, não havendo um rompimento definitivo do autor com sua pátria; 2) agosto de 1968, quando se tornou refugiado político após protestar no jornal Le Monde contra a intervenção na Tchecoslováquia (MICHALSKI, 2013, sem paginação). Nota-se que em 1978 Mrożek recebeu a cidadania francesa (COVENEY, 2013, sem paginação), o que demonstra sua situação de emigrante que adquire outra nacionalidade após viver tempo considerável no país de acolhimento, escolhido para viver.

Em 1964, o dramaturgo alcançou fama mundial com a peça Tango, obra que foi encenada no Brasil em 1972 e que resultou na visita do autor ao Brasil. Nota-se que dramaturgo era mais afeito ao trato das palavras escritas do que da oratória, sendo seu laconismo uma forma de agir no mundo, através da observação. O que ele observava seria utilizado na sua produção escrita. Motivo pelo qual vários de seus textos apresentavam pessoas vivendo sob um regime autoritário.

\footnotetext{
${ }^{1}$ PRL - Polska Rzeczpospolita Ludowa, nome oficial da Polônia durante os anos 1952-1989, período em que ficou sob influência da União das Repúblicas Soviéticas.
} 
A complexidade da vida percebida por Mrożek é refletida no que ele escreveu sobre emigração e seus dilemas na sua correspondência com amigos, nas quais discorreu sobre o sentido de "estar em casa" e "sentir-se um estranho". Ainda, na sua produção artística notamos que a obra Emigranci (Os Emigrantes) aborda essa temática. No texto estão retratados dois poloneses no exílio e, ao mesmo tempo, a condição universal de exilado através de personagens multidimensionais (DĄBROWSKA, 2013, sem paginação).

O retorno à pátria só ocorreu em 1996, quando a Polônia estava em situação diferente de quando ele emigrou, vivendo em Cracóvia até 2008, quando se mudou com sua esposa para Nice (TVN, 2013).

\title{
Zbigniew Herbert
}

Zbigniew Herbert nasceu em 29 de outubro de 1924 em Lwów, na época território polonês, que hoje é Lviv, na Ucrânia. Sua família participava do cenário cultural da cidade e o pai do poeta foi o responsável pelo primeiro contato do escritor com a literatura, ao ler Pan Tadeusz (O Senhor Tadeu) de Adam Mickiewicz e a Trilogia de Henryk Sienkiewicz. Com a Segunda Guerra Mundial, a família teve que abandonar a cidade (KILANOWSKI, 2018, p. 36, 48-49, 55).

Segundo Nelson Ascher (2008, sem paginação),

\begin{abstract}
Herbert viveu no palco de batalhas sangrentas e conviveu com um amplo leque de tiranias. A história, para ele, era inescapável. Se ser polonês a tornava mais terrível, nem por isso sua perspectiva se reduz à de seu país, pois este foi apenas o lugar no qual ele assistiu ao suicídio da civilização européia.
\end{abstract}

Herbert era conhecido pela erudição incomum e por seu bom humor, o que desembocava em sua atitude de pregar peças nas pessoas de seu círculo de relações (KILANOWSKI, 2018, p. 84).

De acordo com Piotr Kilanowski, Herbert sempre teve tendência de falar pelos oprimidos, pelas pessoas cuja voz foi extinta ou calada, cuja memória foi maculada pela propaganda comunista; cuja vida foi atacada pela guerra, literal ou metaforicamente (KILANOWSKI, 2018, p. 96).

Começou a escrever poesias durante a Segunda Guerra Mundial, sendo publicadas em periódicos em 1950 e que se tornaram conteúdo de livros somente em 1956 e 1957, abarcando a produção dos 12 anos antecedentes (CARPENTER; CARPENTER, 1980, p. 38). 
O poeta enfocado nesse estudo nunca aceitou orientações sobre o que deveria escrever, ou seja, a censura. $\mathrm{O}$ fato de suas obras terem sido traduzidas e por ter vivido no Ocidente por longos períodos, fizeram ele ser imune às sanções econômicas que as autoridades impunham na época do comunismo na Polônia (COETZEE, 1990-1991, p. 160). O que não significa que não tenha enfrentado adversidades financeiras ao longo da vida, como comentado por Piotr Kilanowski em inúmeras passagens de sua tese de doutorado, já objeto de referência no presente trabalho.

Piotr Kilanowski comenta que a vida de Herbert foi marcada por deslocamentos, seja entre cidades de diversas regiões da Polônia e as fora desse país. De modo que, mesmo sempre voltando à pátria, passou vinte anos fora de sua terra natal, tendo voltado definitivamente em 1992 (KILANOWSKI, 2018, p. 146-147, 151).

Em 28 de julho de 1998 ele faleceu (KILANOWSKI, 2018, p. 496).

\section{CONTEXTO: EMIGRAÇÃO}

Como já mencionado no item anterior, Mrożek e Herbert viveram muitos anos longe de sua pátria. Decorrência do regime político vigente na Polônia no período entre 1952 e 1989.

Segundo Zbigniew Jarosiński, o contexto cultural do pós-guerra teve a orientação marxista e comunista em primeiro plano, sendo isso um reflexo do ambiente vivenciado no período entreguerras e no prestígio da União Soviética por sua atuação contra o fascismo (JAROSIŃSKI, 2007, p. 15). Algo que se pode perceber na produção da década de 1940, na qual muitos estudiosos entendiam que a emergência do comunismo na Europa Oriental seria uma revolução social contra o fracasso da democracia, depressão econômica e luta étnica presentes no período do entre guerras (MAZOWER, 2001, p. 250). Segundo o historiador Mark Mazower

Havia entusiasmo pela União Soviética e respeito por suas realizações. O enorme prestígio que o Exército Vermelho conquistara ao derrotar o Terceiro Reich não desapareceu de imediato com o mau comportamento de seus soldados. Ademais, a derrota do Terceiro Reich não afastou os tradicionais temores do poderio alemão: ao contrário, a experiência de meio século e sobretudo dos seis anos anteriores convenceu muita gente de que a proteção russa era, mais que nunca, uma garantia necessária contra a futura expansão da Alemanha (MAZOWER, 2001, p. 254).

Ao referir-se à Polônia, Jacek Kurczewski afirmou que "Embora a nação não quisesse aceitar o sistema de governo imposto por Stalin, nos primeiros anos do pós- 
guerra a maioria rejeitou a guerra civil e optou pela reconstrução de casas para a população e do país como a casa de todos" (KURCZEWSKI, 1993, p. 10 apud MAZOWER, 2001, p. 254-255). Assim, a justiça social e eficiência econômica eram metas mais relevantes do que a democracia, sendo que o comunismo, nessa situação, indicou um caminho para desenvolvimento pelo meio-termo da democracia popular (MAZOWER, 2001, p. 255).

Isto é algo que permite compreender o posicionamento inicial de Mrożek sobre o comunismo. Segundo Celina Juda, Mrożek escreveu, durante um tempo, seguindo as exigências do realismo socialista (JUDA, 1992, p. 194 apud ŚCISŁOWSKA, 2012, p. 34). A fascinação pelo comunismo não perdurou na sua vida, mas em nenhum momento negou que teve fé no regime, sendo que essa passou a ceticismo e depois negação (DĄBROWSKA, 2013, sem paginação).

Situação diferente foi vivenciada por Herbert. Segundo A. Alvarez (apud POETRY FOUNDATION, sem paginação), esse poeta seria um político por estar sempre e cautelosamente na oposição. A oposição dele não seria dogmática e se basearia, na verdade, na recusa de abandonar sua própria verdade e seus próprios padrões diante de qualquer dogma.

Entretanto, na Polônia os conflitos logo surgiram devido à impopularidade do comunismo e da Rússia no país, havendo resistência à dominação russa. Mas mesmo assim, a política adotada no princípio da dominação comunista objetivava conquistar apoio (MAZOWER, 2001, p. 255-256). Nota-se que a instituição do Realismo Socialista na Polônia resultou numa significativa mudança na vida cultural, a saber: 1. o patrocínio do Estado à produção cultural, sendo que exigia obediência às suas orientações, definições de tarefas e funções; 2. Intenção de implantar o padrão ideológico do partido na cultura (JAROSIŃSKI. 2007, p. 43). O Realismo Socialista vigorou entre os anos 1949-1953.

Joanna Wilk-Racieska menciona que o período mais duro do regime autoritário foi quando estava no poder Bolesław Bierut (1947-1952 como presidente, 1952-1954 como Primeiro-Ministro), o qual serviu aos interesses da União Soviética, dirigiu o processo de sovietização e foi responsável pelo clima de terror e repressão contra os anticomunistas (WILK-RACIESKA, 2016, p. 107).

Nesse contexto, todas as esferas do cidadão são penetradas pelo sistema político e a literatura foi utilizada como ferramenta ideológica da propaganda. Um exemplo é o Estado financiar a produção literária e proporcionar elevado status social aos escritores, os quais, como contraprestação, devem seguir os ditames ideológicos e poéticos em vigor. Ao passar do tempo, os autores financiados exigem liberdade para criação e recebem como resposta, o aumento da censura (WILK-RACIESKA, 2016, p. 133). 
Segundo Joanna Wilk-Racieska, o segundo período de Socialismo Real se inicia com a eleição de Władysław Gomułka para o cargo de primeiro secretário do Polska Zjednoczona Partia Robotnicza, abreviado como PZPR (POUP - Partido Operário Unificado Polonês) cargo que ocupou entre 1956 a 1970. Gomułka apresentava discurso de que o povo polonês se situava acima da doutrina, o que despertou as esperanças por mudanças. Houve mudanças sociais como a anulação da coletivização da agricultura iniciada pelo seu predecessor. Entretanto, o regime se endureceu e começou a reprimir os críticos. A sangrenta repressão aos movimentos foi reprovada inclusive por pessoas de dentro do partido e isso causou a saída de Gomułka e início do penúltimo período desse regime na Polônia (WILK-RACIESKA, 2016, p. 108).

O penúltimo período teve a censura mais branda, tornava possível comprar mais produtos e obter passaporte para viajar de férias ao exterior. A subida de preços causou novas revoltas obreiras em junho de 1976, mas em agosto de 1980, o panorama era mais grave: a situação política e crescente crise econômica, intensificação da pressão ideológica aos cientistas e universidades. O que decorreu na convocação de greves de trabalhadores, estudantes e intelectuais, que gerou o nascimento do sindicato Solidarność (Solidariedade) (WILK-RACIESKA, 2016, p. 109).

Em 13 dezembro de 1981, foi declarada a lei marcial - estado de guerra, reduzindo drasticamente as já limitadas liberdades civis e efetuando prisão de dissidentes (WILKRACIESKA, 2016, p. 110). Durante um período, a medida conseguiu reestabilizar o sistema. No fim da década de 1980, a crise ressurgiu mais aguda, exigindo mudanças radicais. Não houve pressão direta ou indireta contra essas mudanças por parte dos soviéticos e o sistema começou a se desmontar (WIATR, 1990, p. 72). Em 1989, o general Jaruzelski teve que retomar as conversações com o Solidariedade, o que desencadeou em eleições, em junho do mesmo ano, vencidas por esse movimento de várias dimensões (sindical, política, com conotação nacionalista e católica) e a compartilhar o poder com os comunistas (REIS FILHO, 2003, p. 147).

As mudanças políticas no Centro-Leste Europeu contaram com uma revolução (na Hungria, em 1956) e muitos movimentos reformadores como em Praga em 1968 e na Polônia em 1980 e 1981 (VISEGRÁDY, 2011, p. 15). Segundo Mazower, a Primavera de Praga foi mais ameaçadora para Moscou que o levante húngaro de 1956, porque a revolta se originou no próprio partido (MAZOWER, 2001, p. 280).

Toda essa situação de repressão e a condição de vida proporcionada à população fez com que muitos emigrassem, algo que pode ser percebido nas obras escolhidas para análise comparada desse trabalho. 


\section{ANÁLISE COMPARADA DOS TEXTOS EMIGRANCI (OS EMIGRANTES) E PAN COGITO - POWRÓT (SENHOR COGITO - O REGRESSO)}

Emigranci (Os Emigrantes) é uma peça em um ato. Seu enredo, basicamente, é a conversa entre duas pessoas que dividem um porão como moradia em algum país estrangeiro ocidental. As personagens são: AA é um emigrante político, intelectual que detém posses e XX que emigrou para acumular dinheiro através de trabalho braçal ou pouco qualificado em outro país. A conversa possui temas que variam e/ou são retomados ao longo do texto. As sequências narrativas não são lineares e os respectivos inícios são marcados com pausas, sons externos e/ou ações dos personagens que destoam do diálogo e/ou que as precedem. Em alguns desses momentos estão didascálias.

O poema Pan Cogito - Powrót (Senhor Cogito - O Regresso) apresenta o narrador em terceira pessoa que relata sobre a situação do personagem Pan Cogito (Senhor Cogito) no momento em que esse decide regressar à sua pátria e seus pensamentos sobre essa decisão, praticamente apresentando um fluxo de consciência da personagem. O texto está dividido em duas partes, sendo que na primeira a personagem anuncia a sua decisão e inicia seu retorno ao seu país. Na segunda mostra os questionamentos enfrentados por Pan Cogito (Senhor Cogito) após ter adentrado na terra natal. Na forma da disposição dos versos é possível ver certos vazios, condensações de palavras que podem significar o pensamento reticente do herói.

Importante ressaltar que as obras ora analisadas foram publicadas no mesmo ano: 1974. Ambas têm como personagens pessoas que emigraram, como os autores dos textos. Por questões de atender o enfoque proposto, ou seja, a questão da emigração, serão trabalhados trechos das mencionadas obras.

A sensação de inadequação do emigrante no território em que se fixou está presente nas duas obras. No poema destaca-se o seguinte trecho:

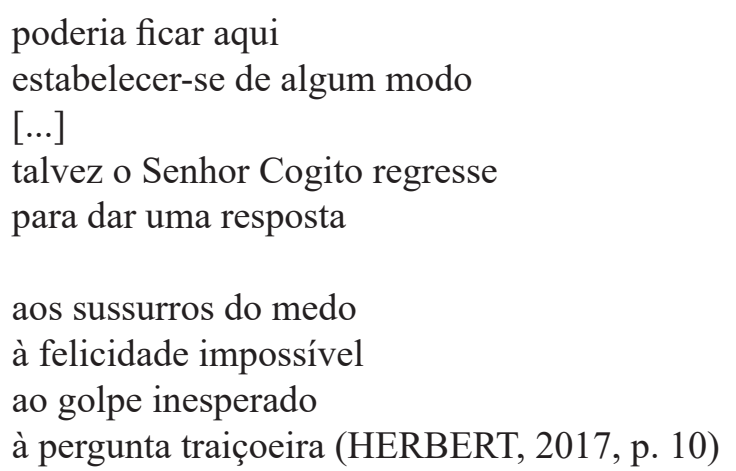


E no texto de Mrożek cabe reproduzir uma das falas do personagem AA:

\begin{abstract}
AA - A mnie to wszystko przypomina bebechy. Żyjemy tu jak dwie bakterie we wnętrzu jakiegoś organizmu. Dwa obce ciała. Pasożyty albo coś jeszcze gorszego. Bo może my jesteśmy jak jakieś dwie bakterie chorobotwórcze? Czynniki rozkładu w zdrowym organizmie. Prątki, laseczniki Kocha, wirusy, gonokoki? Ja - gonokok, ja, który uważałem się zawsze za drogocenną komórkę najwyżej rozwiniętej, mózgowej substancji. Tam, u nas, dawniej... za szlachetnego neurona, za cząstkę, która jest już na samym pograniczu materii, która jest nie tylko materią, która jest czymś już wyższym ponad materię... A teraz gonokok. W jakichś flakach. Gonokok w towarzystwie pierwotniaka. (MROŻEK, 2000, p. 451).
\end{abstract}

(AA - Isso tudo me lembra tripas. Vivemos aqui como duas bactérias no interior de um organismo. Dois corpos estranhos. Parasitas ou algo ainda muito pior. Pode ser que sejamos como duas bactérias patogênicas? Elementos de podridão em um corpo saudável. Bacilos, bacilos de Koch, vírus, gonococos? Eu, um gonococo, eu que sempre me considerei como uma preciosa célula do cérebro mais desenvolvido. Lá, na nossa terra, antigamente... por um neurônio nobre, por uma partícula, que quase não é mais matéria, que está no limiar da matéria, que não é apenas matéria, que é algo maior que a própria matéria... E agora gonococo. Dentro das tripas. Gonococo na companhia de um protozoário. ${ }^{2}$ )

Em ambos se nota que a forma que o indivíduo pensa sobre si ou seu objetivo são modificados na vivência no estrangeiro. Nesse espaço a felicidade é impossível, porque o emigrante é um corpo estranho na nova sociedade. $\mathrm{O}$ emigrante pode trazer modificações para os que estão em seu entorno (podridão/incômodo) e não saber como se comportar pelos ditames da cultura desse novo ambiente, porque tudo the causa receio. Algo ampliado no contexto em que muitas pessoas dissidentes de governos comunistas eram vigiadas tanto pelo seu país como no local onde se fixavam.

O medo pode ser entendido como inquietação da pessoa diante da situação em que se encontra, resultado de sua decisão para escapar do jugo do governo totalitário. Ainda, como a consciência de que a existência humana é finita e minúscula dentro da história. O ser humano seria uma peça na grande engrenagem da natureza. Algo que causa desconforto, pois a humanidade, em geral, se coloca em uma posição acima da

\footnotetext{
${ }^{2}$ Salvo indicação em contrário, as versões em português de Emigranci são traduções livres da autora do presente trabalho. Desde já se expressa o agradecimento a Piotr Kilanowski, que colaborou com a tradução com sugestões e observações.
} 
natureza e a percepção de que a última é maior, desmonta a vã ideia de que se pode fugir desse componente natural, de ser animal pelo simples fato de ser dotado de racionalidade. A inadequação por estar em lugar além da sua pátria e não se sentir como parte dessa nova sociedade, devido à experiência, na sua terra natal, que tolhia sua vontade ser diametralmente oposta à experiência de liberdade no novo espaço.

Em relação ao texto Emigranci, é possível dizer que a bactéria e a célula neural são equivalentes por estarem inseridos num grande mundo do qual dependem, vivem e atuam. Mas cada uma deve estar em seu lugar. Caso sejam retiradas desse meio, podem morrer, causar problemas e não podem mudar sua natureza pelo simples fato de estarem em novo ambiente.

Cabe indicar que no trecho da obra poética analisada, também está presente a inadequação do emigrante ao regressar à sua pátria, pois dentro do regime totalitário ele é ameaçado e objeto de perseguições. Isso faz que o emigrante ao retornar, sinta-se como um estrangeiro dentro da realidade vivenciada na sua terra natal.

Outra indicação da inadequação do emigrante, que está em outro país que não o seu, é a língua pela qual ele se expressa. Os seguintes versos de Herbert são demonstrativos disso:

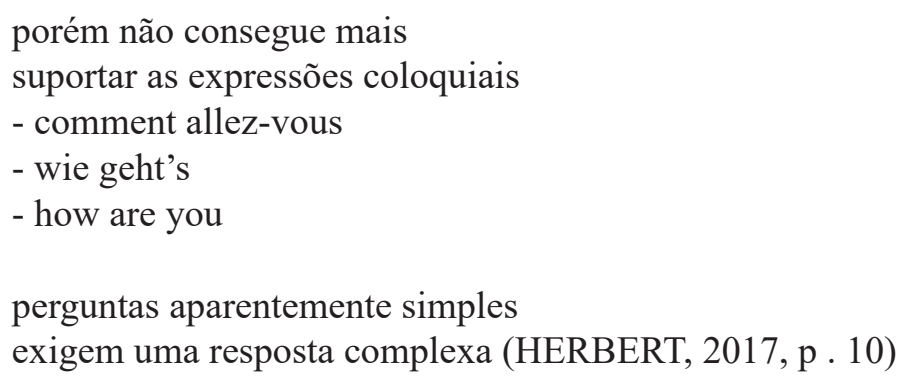

E no seguinte diálogo da peça:

AA - Dlaczego się nie uczysz języka? (XX krztusi się w dalszym ciagu, ale już sztucznie, żeby zyskać na czasie) Pytam, dlaczego się nie uczysz języka!

$\mathrm{XX}$ - Jakiego języka?

AA - Obcego!

XX (wyjmuje ręce z kieszeni, ogląda je. Ręce trzesa mu się w dalszym ciagu) - Zaraz mi przejdzie. (chowa ręce do kieszeni)

AA - Odpowiesz mi czy nie?

$\mathrm{XX}$ - To znaczy po ichniemu?

AA - Nie irytuj mnie. Wiesz dobrze, o co cię pytam. W tym kraju jesteś analfabetą. Gorzej - głuchoniemym. Kiedy wreszcie przestaniesz być 
kaleką?

$\mathrm{XX}$ - Ja po ichniemu gadał nie będę.

AA - Dlaczego? Żyjesz przecież tutaj, w tym kraju, jesz, pijesz, chodzisz ulicami, jak inni ludzie. Więc dlaczego nie chcesz mówić jak oni? Mógłbyś znaleźć lepszą pracę...

$\mathrm{XX}$ - To nie są ludzie.

$\mathrm{AA}-\mathrm{Nie}$ ?

$X X-$ Nie. Tutaj nie ma ludzi.

AA - A gdzie są, twoim zdaniem?

XX - U nas (MROŻEK, 2000, p. 479-480)

(AA - Por que você não está aprendendo a língua? (na sequência $X X$ tem tosse carregada, mas é dissimulada, para ganhar tempo) Pergunto, por que não está aprendendo a língua!

XX - Que língua?

AA - A estrangeira.

XX (tira as mãos dos bolsos e as observa. Suas mãos ainda tremem) Logo vai passar. (coloca as mãos nos bolsos)

AA - Vai me responder ou não?

XX - Quer dizer na fala deles?

AA - Não me irrite. Sabe bem, o que eu te pergunto. Nesse país você é um analfabeto. Pior - um surdo-mudo. Quando, afinal, vai deixar de ser um aleijado?

$X X$ - Eu não vou falar na fala deles.

AA - Por quê? Você vive aqui, nesse país, come, bebe, anda nas ruas como qualquer pessoa. Então, por que não quer falar como eles? Você poderia encontrar um trabalho melhor...

XX - Eles não são gente.

$\mathrm{AA}-\mathrm{Não}$ ?

$X X$ - Não. Aqui não tem gente.

AA - E na sua opinião, onde tem gente?

XX - No nosso país.)

A barreira linguística é outro obstáculo que evidencia a inadequação do emigrante no novo país. Não poder se expressar com naturalidade em sua própria língua no cotidiano e ter que responder na língua estrangeira algo aparentemente simples significa grande esforço mental e corporal. Corporal, pela questão de como pronunciar certos sons e/ou pelos gestos utilizados, pois a comunicação não verbal também é necessária na interação social. Não saber se expressar oralmente de maneira inteligível aos outros é uma situação sufocante e faz com que o indivíduo se questione sobre sua própria identidade. Isso porque, a integração na sociedade que lhe recebeu pode significar o rompimento dos laços com sua pátria e uma ressignificação de seu mundo. Nesse caso, a língua não seria apenas ferramenta de comunicação, seria ainda uma forma de preservar a cultura do país de origem e suas raízes. 
No poema estão expressões em francês, alemão e inglês cuja tradução para português seria "como você está" que naturalmente já se lê como pergunta, não é algo comum que um polonês faça numa conversa descompromissada e/ou com desconhecidos, com intuito de iniciar diálogo ou cumprimentar alguém. Algo que evidencia o choque cultural entre o emigrante e o meio onde vive. É possível dizer que a fala de XX sobre a população do país de acolhimento não ser pessoas signifique uma grande aversão à cultura de onde está e/ou que não se sente recebido nesse ambiente.

Ainda, é admissível entender que a dificuldade no uso da palavra seja reflexo da percepção de que a vida não pode ser traduzida em palavras, porque os momentos são dotados de multiplicidade de visões e a escolha do vocabulário limitaria expressar a totalidade disso. O que permite dizer que o ser humano, mais uma vez, percebe a restrição da racionalidade diante da natureza.

Portanto, notamos que a sensação de inadequação do emigrante está representada nas duas obras de maneira semelhante, a saber: não estar confortável no novo país, consigo mesmo e com a língua desse lugar.

\section{AGRADECIMENTOS}

Ao professor Dr. Marcelo de Paiva Souza que me orientou no Projeto de Iniciação Científica em 2018/2019, no qual houve enfoque na análise da obra dramática aqui trabalhada. E ao professor Dr. Piotr Kilanowski pela colaboração no processo de tradução de Emigraci. 


\section{REFERÊNCIAS:}

ASCHER, Nelson. O sr. Cogito: Marcado por versos atuais, poeta polonês do século 20 precisa ser traduzido no país. Folha de São Paulo, São Paulo, sem paginação, 14 abr. 2008, Ilustrada. Disponível em: <https://www1.folha.uol.com.br/fsp/ ilustrad/fq1404200820.htm>. Acesso em 24 nov. 2018.

CARPENTER, John; CARPENTER, Bogdana. Zbigniew Herbert: The Poet as Conscience. The Slavic and East European Journal, Columbus, v. 24, n. 1, p. 37-51, 1980. Disponível em: $<$ https://www.jstor.org/stable/307340?read-now=1\&seq=1\#page_scan_tab_contents $>$. Acesso em 24 nov. 2018.

COETZEE, J. M. Zbigniew Herbert and the Figure of the Censor. Salmagundi, Saratoga Springs, n. 88/89, p. 158-175, 1990-1991. Disponível em: <https:/www.jstor.org/ stable/40548475?read-now $=1 \&$ refreqid $=$ excelsior\%3Aef5c151ee43669d08e8393ed9a3 3efea\&seq=3\#page_scan_tab_contents $>$. Acesso em 24 nov. 2018.

COVENEY, Michael Sławomir Mrozek obituary. The Guardian, Londres, sem paginação, 21 ago. 2013. Disponível em: <https:/www.theguardian.com/world/2013/aug/21/ slawomir-mrozek>. Acesso em 18 nov. 2018.

DĄBROWSKA, Krystyna. Stawomir Mrożek. , sem paginação, set. 2009, atualizado em ago. 2013. Disponível em: <https://culture.pl/pl/tworca/slawomir-mrozek>. Acesso em: 14 ago. 2018.

HERBERT, Zbigniew. O Senhor Cogito - o regresso. Pan Cogito - powrót. Tradução de Piotr Kilanowski. Relevo, Curitiba, v. 6, ano 7, p. 10, 2017. Disponível em: $<$ https://issuu. com/jornalrelevo/docs/relevo_-_edi___o_de_fevereiro_de_2>. Acesso em $01 \mathrm{abr} .2019$.

JAROSIŃSKI, Zbigniew. Pierwsze lata. Literatura przed 1949 rokiem. In: JAROSIŃSKI, Zbigniew. Literatura lat 1945-1975. Varsóvia: Wydawnictwo Naukowe PWN, 2007. (Mała historia literatury polskiej). p. 9-40.

JAROSIŃSKI, Zbigniew. Socrealizm w literaturze krajowej. In: JAROSIŃSKI, Zbigniew. Literatura lat 1945-1975. Varsóvia: Wydawnictwo Naukowe PWN, 2007. (Mała historia literatury polskiej). p. 42-80. 
KILANOWSKI, Piotr. Dos exilados aos ex-humanos - um passeio pelos abismos da desumanização. Antígona em Nova Iorque, de Janusz Głowacki, Os Emigrantes, de Sławomir Mrożek e Esperando Godot, de Samuel Beckett, em diálogo. Qorpus, Florianópolis, v. 2016/2, n. 21, 2016. Disponível em: $<$ http://qorpus.paginas.ufsc.br/como-e/edicao-n-21/dos-exilados-aos-ex-humanosum-passeio-pelos-abismos-da-desumanizacao-antigona-em-nova-iorque-de-januszglowacki-os-emigrantes-de-slawomir-mrozek-e-esperando-godot-de-samuel-beckettem-dialogo/>. Acesso em 26 maio 2019.

KILANOWSKI, Piotr. “Queria permanecer fiel à clareza incerta...”: Sobre poesia de Zbigniew Herbert. 2018. 876 p. Tese (Doutorado em Literatura) - Centro de Comunicação e Expressão, Programa de Pós-Graduação em Literatura, Universidade Federal de Santa Catarina, Florianópolis, 2018.

MAZOWER, Mark. A construção da democracia popular. In: MAZOWER, MARK. Continente sombrio: A Europa no século XX. Tradução Hildegard Feist. São Paulo: Companhia das Letras, 2001. p. 248-281.

MICHALSKI, Cezary. Mrożek jako emigrant. Krytyka Polityczna, Varsóvia, sem paginação, 15 ago. 2013. Disponível em: <http://krytykapolityczna.pl/kultura/czytajdalej/michalski-mrozek-jako-emigrant/>. Acesso em: 5 set. 2018.

MROŻEK, Sławomir. Emigranci (1974). In: MROŻEK, Sławomir. Wybór dramatów. Varsóvia: Noir sur Blanc, 2000. p. 419-520.

POETRY FOUNDATION. Zbigniew Herbert. sem paginação. Disponível em: $<$ https://www.poetryfoundation.org/poets/zbigniew-herbert>. Acesso em 24 nov. 2018.

REIS FILHO, Daniel Aarão. 6. A Perestroika e a desagregação da União Soviética In: REIS FILHO, Daniel Aarão. As revoluções russas e o socialismo soviético. São Paulo: Editora UNESP, 2003. (Coleção Revoluções do século XX - Direção de Emília Viotti da Costa). p. 135-156.

ŚCISŁOWSKA, Iwona. Groteska jako literacki sposób ukazania rzeczywistości doby socrealizmu w Polsce i Bułgarii (na wybranych przykładach). Heteroglossia Studia Kulturoznawczo-Filologiczne, Bydgoszcz, n. 2, p. 33-52, 2012. Disponível em: $<$ http://www.kpbc.ukw.edu.pl/Content/81544/heteroglossia2-druk.pdf $>$. Acesso em 8 nov. 2018.

TVN. Sławomir Mrożek nie żyje. 2013. (9min21s). Disponível em: <https://www.tvn24. pl/raporty/slawomir-mrozek-nie-zyje,720>. Acesso em 18 nov. 2018. 
VISEGRÁDY, Antal. Um balanço das transformações democráticas no Centro-Leste Europeu. tradução de Andityas Soares de Moura Costa Matos e Pryscilla Gomes Matias. Revista Brasileira de Estudos Políticos, Belo Horizonte, n. 103, p. 11-40, jul./dez. 2011. Disponível em: <https://pos.direito.ufmg.br/rbep/index.php/rbep/article/viewFile/ P.0034-7191.2011v103p12/133>. Acesso em 13 out. 2018.

WIATR, Jerzy J.. Europa do leste: reforma ou queda do sistema? Tradução de Thaddée de Sulocki. Lua Nova, São Paulo, n. 22, p. 69-105, dez. 1990. Disponível em: $\quad<$ http://www.scielo.br/scielo.php?script=sci_arttext\&pid=S0102-6445199000020 0005\&lng=en\&nrm=iso $>$. Acesso em 13 out. 2018.

WILK-RACIESKA, Joanna. El humorismo como uno de los mecanismos unificadores para el pueblo en la época del socialismo real en Polonia. Tempo e Argumento, Florianópolis, v. 8, n. 18, p. 102-133, maio-ago. 2016. Disponível em: <http://www.revistas.udesc.br/ index.php/tempo/article/viewFile/2175180308182016102/6041>. Acesso em 13 out. 2018. 